\title{
O DESENVOLVIMENTO PROFISSIONAL DA DOCÊNCIA NA FORMAÇÃO DE PROFESSORES FACE A UTILIZAÇÃO DAS TECNOLOGIAS
}

CDD: $\mathbf{3 7 1 . 3 0 7 8}$

\author{
Stela C. Bertholo Piconez \\ Andrea Cristina Filatro
}

\section{RESUMO}

Neste artigo, descrevemos as contribuições das abordagens de Design Instrucional e do Learning Design para a organização do trabalho pedagógico no STEA - Sistema Transversal EnsinoAprendizagem que emprega recursos tecnológicos na educação apoiado pelos dados de pesquisa qualitativa e perspectivas teórico-descritivas, em um estudo de caso brasileiro. A abordagem pedagógica na qual o sistema está baseado permeia, em toda sua documentação e práxis: as teorias socioconstrutivistas de Piaget e Vygotsky, os estudos de Ausubel sobre organização dos conceitos prévios da aprendizagem significativa, a concepção de autonomia e liberdade de Paulo Freire, a tipologia conceitual dos conteúdos procedimentais e atitudinais de Zabala bem como a perspectiva andragógica de Knowles que fundamentam a tomada de decisões durante o processo de ensino. Contempla todos os processos de design instrucional - desde planejamento, concepção, implementação, execução e avaliação até a formação e avaliação contínua dos docentes em serviço. Confronta as etapas teórico-práticas do projeto com a abordagem de organização do trabalho pedagógico realizado em um sistema nacional de ensino-aprendizagem, ancorado em bases pedagógicas explícitas, elaborado através de duas décadas de investigação e de práxis. O estudo também inclui material didático produção e ações complementares de investigação acadêmica, contextualizada. Como resultado apresenta as reflexões sobre o projeto de aprendizagem, seus benefícios e desafios e suas contribuições para a inovação no campo da tecnologia educacional. O STEA foi construído de acordo com um modelo pedagógico cuja delimitação conceitual abraça objetivos, organização de conteúdos e metodologias relacionada a diferentes domínios do conhecimento. A elaboração desse modelo atende as necessidades educativas especiais de duas comunidades com características distintas de aprendizagem: a dos jovens e adultos em curso de ensino médio e a formação em ação de estagiários das licenciaturas.

\section{PALAVRAS-CHAVE}

Formação educadores-estagiários; Design instrucional; Design da aprendizagem; Organização do trabalho pedagógico; Ambiente virtual de aprendizagem 


\title{
THE PROFESSIONAL DEVELOPMENT OF TEACHING IN TEACHER'S FORMATION VIS-A-VIS THE USING OF TECHNOLOGIES
}

\begin{abstract}
In this paper, we describe the contributions of instructional design and Learning Design approaches to pedagogical work organization of STEA - Transversal Teaching-Learning System that employs technological resources in education supported by the use of qualitative research approach and theoretical-descriptive perspectives, we compare theoretical and practical framework of instructional design and Learning Design in a Brazilian case study, which contemplates all of instructional design processes - since planning, design, implementation, execution and evaluation until formation and continuing evaluation of acting teachers. Pedagogical approach, which is the system is based on, is clearly declared and permeates all its documentation and praxis: Piaget and Vygotsky's socioconstructivists theories, Ausubel's studies about students' previous knowing organization, Paulo Freire's conception of autonomy and freedom, the conceptual typology of Zabala's procedural and behavioural contents, and Knowles' andragogic perspective grounds the decisions to been made during teaching process. Describes and analyses the confrontation of theoretician-practical steps of Learning Design approach with pedagogical work organization accomplished in a national teachinglearning system, which is anchored in explicit pedagogical bases, ripened through two decades of research and praxis. The study also encompasses didactical material production and complementary actions of academic research. As results, it represents the reflections about Learning Design benefits and challenges, and its contributions to innovation in educational technology field. STEA was built according to a proper, pedagogical model which its conceptual delineation embraces objectives, organization of contents and methodologies related to different knowledge areas. The elaboration of this model attends particular educational needs of two distinct communities with regard to learning characteristics: young and adult learning during high school course and the formation of educatorstrainees to play their roles.
\end{abstract}

\section{KEYWORDS}

Formation educators-trainees; Instructional design, Learning design, Pedagogical work organization, Virtual learning environment 


\section{INTRODUÇÃO}

A qualidade do sistema educativo de um país depende, em grande parte, de seus docentes. As práticas docentes têm efeito relevante sobre o ensino e a aprendizagem. E a natureza da profissão docente requer formação sólida e inovadora diante dos desafios e mudanças decorrentes da presença das tecnologias de informação e de comunicação. O aprendizado eletrônico como solução contemporânea para as demandas sociais por educação tem trazido mudanças paradigmáticas da teoria e prática educacional em contraste com a complexidade dos processos de ensino-aprendizagem

Este artigo situa a posição do formador de formadores que é quem se dedica à formação de mestres e professores, e realiza diversas tarefas, não apenas na formação inicial e permanente de docentes, como também em planos de inovação, assessoria, planejamento e execução de projetos nas áreas de educação, estágios curriculares formal e informal. No âmbito da investigação das contribuições das tecnologias de informação e de comunicação apresenta o STEA - Sistema Transversal de Ensino-Aprendizagem, sistemática de planejamento do trabalho pedagógico e uso das tecnologias de informação e de comunicação.

Muitos fatores podem ser responsáveis por uma sólida formação de professores, tais como a exigência de experiência docente dos formadores, rigorosa formação científica e didática, conhecimento das principais linhas de aprendizado que as sustentam, estar apto a trabalhar com a contemporaneidade das tecnologias articuladas à educação escolar e, finalmente, preparo para ajudar os docentes a refletir e realizar as mudanças comportamental, conceitual e metodológica hoje exigidas pelo sistema educativo.

Além destes, a multiplicidade e a diversidade das estratégias para formação de formadores sempre foram poucos exploradas no campo da pesquisa sobre formação docente. As modalidades de Estágios Curriculares Supervisionados nem sempre contemplam concretas situações de salas de aula na educação escolar como um todo. Programas curtos e planos de estudos altamente teóricos sacrificam a prática em sala de aulas e a preparação das matérias, aspectos fundamentais na formação de bons mestres. E a capacitação dos formadores de professores? Tal questionamento pautou nosso aperfeiçoamento dos conhecimentos e habilidades pedagógicas da natureza profissional da carreira docente; forneceu conhecimentos especializados em aspectos em que se diagnosticam claras deficiências (trabalho 
interdisciplinar, design instrucional e learning design) e incentivou a introdução de reformas educativas, de inovações ao currículo face o uso das tecnologias. O desafio culminou com a criação de um núcleo de estudos relevante para a formação inicial e em serviço de professores.

Ao longo dos seus vinte anos de existência, o NEA - Núcleo de Educação de Jovens e Adultos e de Formação Permanente de Professores (Ensino presencial e Educação a Distância) da Faculdade de Educação a Distância da USP, através da tarefa de coordenação científica junto à equipe de professores e colaboradores vinculados - desenvolveu o Sistema Transversal de Ensino-Aprendizagem (STEA), uma metodologia de planejamento para educação de jovens e adultos no ensino fundamental e médio, baseada em um template comum integrando diversos eixos de conhecimento e (re) construído anualmente por professores em formação.

A tarefa de formar professores por meio dos estágios curriculares teve na criação deste espaço e metodologia a resposta ao questionamento sobre a necessidade permanente de atualização alimentada pelas características da universidade: ensino, pesquisa e extensão. $\mathrm{Na}$ articulação desta tríade, desenvolvemos competência pedagógico-didática ensinando aos professores como selecionar entre uma série de estratégias conhecidas, as mais adequadas para intervir intencionalmente, promovendo os aprendizados dos alunos. Os professores conseguem compreender as suas competências político-institucionais enquanto capacidade em articular a macro política referida ao conjunto do sistema educativo com a micro política do que é necessário programar, instituir e avaliar nas instituições. E a competência produtiva que permite aos docentes compreender o mundo em que vivem e viverão, e intervir como cidadãos produtivos. A competência interativa faz que aprendam cada vez mais a conhecer e compreender a cultura dos estudantes, as peculiaridades das comunidades, as formas de funcionamento da sociedade civil e sua relação com o Estado, de exercer a tolerância e a cooperação entre diferentes. 


\section{O STEA - SISTEMA TRANSVERSAL DE ENSINO-APRENDIZAGEM}

O STEA embute um modelo pedagógico próprio, decorrente do delineamento conceitual que abarca objetivos, organização de conteúdos e metodologias relacionados a diferentes domínios do conhecimento. A elaboração de tal modelo originou-se de necessidades educacionais particulares de duas comunidades com características de aprendizagem bem definidas e diferenciadas: a educação de jovens e adultos (para o Curso de Ensino Médio do Programa de EJA) e a formação de professores em serviço (no escopo do Programa de Formação de Professores-Estagiários).

A abordagem pedagógica na qual o STEA se fundamenta está claramente declarada e permeia toda a sua documentação e prática: as teorias socioconstrutivistas de Piaget e Vygotsky, os estudos de Ausubel sobre a organização prévia dos saberes dos alunos, a concepção de autonomia e liberdade de Paulo Freire, a tipologia de conteúdos conceituais, procedimentais e atitudinais de Zabala (1998) e a perspectiva andragógica de Knowles fundamentam as tomadas de decisão durante o processo educativo. Assim sendo, dado o sumário de abordagens pedagógicas de Beetham (2004), o STEA carrega elementos das abordagens: (a) construtivista individual (construção ativa e integração de conceitos, problemas pouco estruturados, oportunidades para reflexão, ambientes interativos e desafios apropriados, encorajamento à experimentação e à descoberta de princípios, adaptação a conceitos e habilidades existentes, desenvolvimento de habilidades metacognitivas, desempenho estendido, valorização de processos tanto quanto de resultados, certificados variados de excelência, auto-avaliação, autonomia na aprendizagem); (b) construtivista social (desenvolvimento conceitual através de atividades colaborativas, oportunidades para discussão e reflexão, ambientes colaborativos, encorajamento a experimentação e descoberta compartilhadas, desenvolvimento de habilidades sociais, valorização da participação tanto quanto dos resultados, responsabilidade compartilhada); e (c) aprendizagem situada (participação em práticas sociais de investigação e aprendizagem, aquisição de habilidades em contextos de uso, desenvolvimento de relações de aprendizagem e profissionais, criação de ambientes seguros para participação. suporte ao desenvolvimento de identidades, facilitação de diálogos e relacionamentos de aprendizagem, elaboração de oportunidades de aprendizagem autênticas, prática autêntica, envolvimento de pares). 
O STEA foi desenvolvido tendo em vista a educação de jovens e adultos, e vem sendo empregado com sucesso nos Cursos de Ensino Fundamental e Médio do Programa de Capacitação Operacional Básica do Departamento de Recursos Humanos da Reitoria da Universidade de São Paulo. Alfabetizou mais de três mil funcionários do campus em nível de escolarização fundamental até a $8^{a}$ série e mais de mil em nível de ensino médio. Em ações externas, o STEA foi utilizado no Programa Alfabetização Solidária para alfabetizar 25 mil alunos nos estados de Ceará, Pernambuco, Alagoas e São Paulo. No Programa de Ensino Fundamental da Cia. Nestlé do Brasil/FAPESP/FINEP, foram atendidos cinco mil funcionários de 17 unidades industriais em São Paulo, Bahia, Minas Gerais e Rio de Janeiro. Foi responsável pela formação de 40 professores, diretores e coordenadores pedagógicos da rede municipal de Santo André no primeiro curso de pós-graduação lato sensu sobre Educação de Adultos e uso das tecnologias. Na rede municipal de São Bernardo do Campo e de Itatiba capacitou mais de 160 professores.

O STEA se distingue por sua natureza adaptável, atualizável e compatível com a legislação específica para os respectivos níveis de ensino (Ensino Fundamental e Médio). Idealizado originalmente para uma modalidade de educação a distância semipresencial apoiada principalmente em material impresso - e complementada por material em vídeo e por recursos didáticos variados -, o STEA disponibiliza a professores e alunos Fichas Temáticas de Apoio Pedagógico. Estas são categorizadas em diferentes eixos de conhecimentos (Linguagens e Códigos, Ciências Humanas, Ciências da Natureza e Matemática) e diferentes disciplinas (Português, Inglês, Geografia, História, Biologia, Física, Química e Matemática) conforme orientações da política educacional do país.

Em relação ao uso das tecnologias, já na década de 1990, o STEA possibilitava a elaboração de projetos coletivos, a socialização e o compartilhamento de projetos de aula através de arquivos em disquetes e, posteriormente em CDs, disponibilização de materiais em uma biblioteca e comunicação assíncrona por meio do correio eletrônico.

Em um projeto financiado pelo Departamento de Recursos Humanos da Reitoria da USP, o Sistema Transversal de Ensino-Aprendizagem foi virtualizado no Portal do NEA. 
O STEA trabalha sob a perspectiva da Pedagogia de Projetos, acreditando que ela “pode transformar a qualidade de ensino” (PICONEZ, 1999, p. 9). No âmbito do STEA, cada episódio-aula é encarado como um projeto e roteiro de aprendizagem (PICONEZ, 1999, p. 18).

O STEA favorece implementação a distância de educação escolar, sob a perspectiva de modelo híbrido, envolvendo atividades individuais e coletivas. O aluno recebe orientações de como estudar tanto presencialmente através de plantões de dúvidas diários e ou pelo Guia Tutorial de Apoio (acessado no Portal NEA ou via material impresso). Mais que uma sistemática de planejamento, o STEA se constitui em uma "representação física" (PICONEZ, 2004a, p. 17) que possibilita atualização permanente com o suporte das tecnologias de informação e de comunicação. Isso é feito através de Fichas Temáticas de Apoio Pedagógico organizadas em blocos disciplinares.

A Ficha Temática é constituída por onze campos que representam a fundamentação metodológica apoiada por referencial teórico baseado nas principais tendências pedagógicas. Representam episódios-aula, identificados no campo 1 pelo título principal, que apresenta o tema global do episódio, e pela unidade temática ligada aos grandes blocos disciplinares.

As Fichas Temáticas de Apoio Pedagógico operacionalizam as reflexões e/ou partes da proposta político-pedagógica do STEA. São compostas pela ficha propriamente dita, por Folhas Anexas e por Folhas-Tarefa, como mostra a figura seguir. 


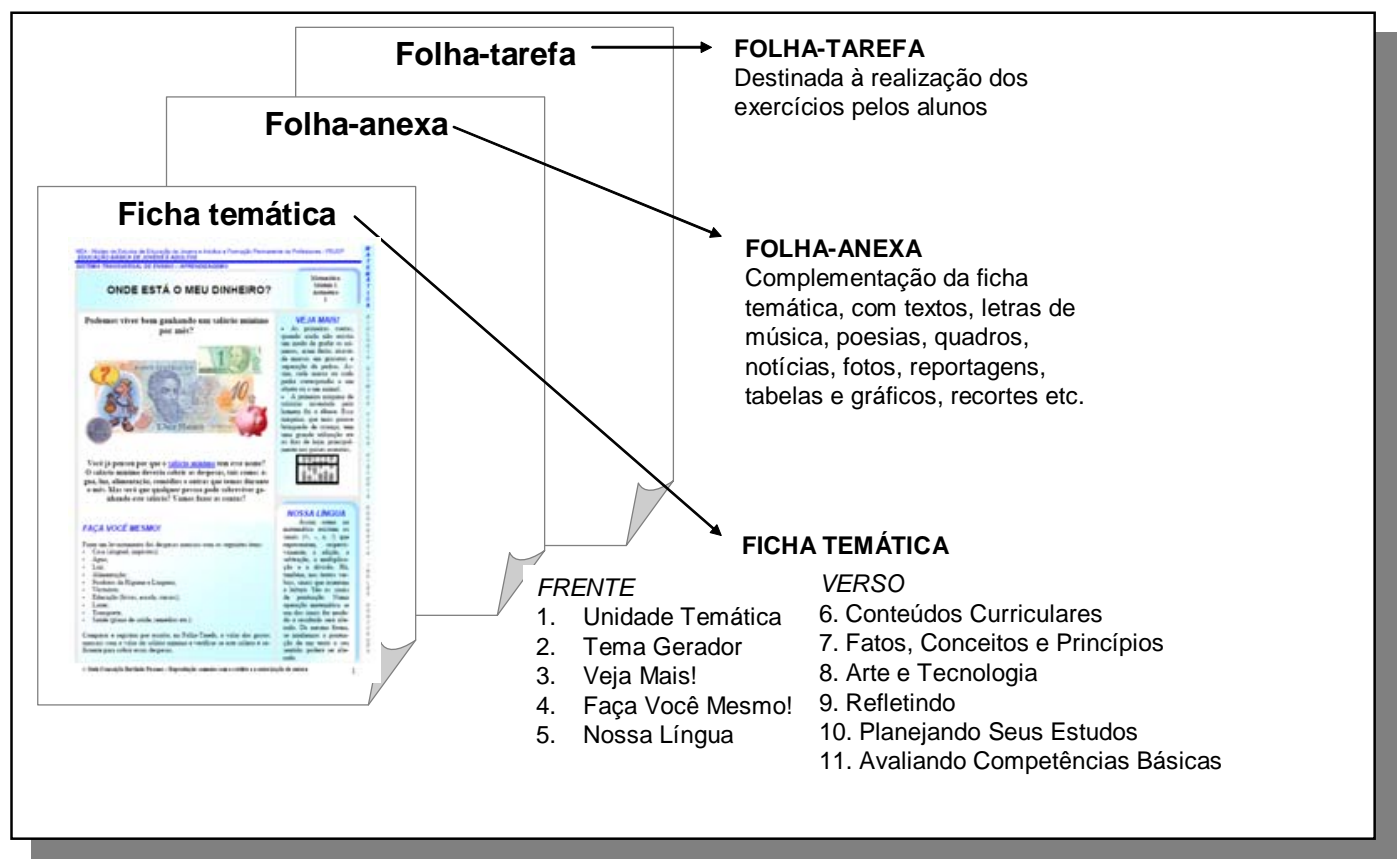

FIGURA 1 - Caracterização do Material Didático do STEA - Sistema Transversal de EnsinoAprendizagem

O campo 2 apresenta o título secundário da unidade temática, a partir de perguntas desafiadoras ou problematizadoras sobre temas de toda a ordem do contexto social vivido pelos alunos. Na chamada Roda de Conversa, os alunos são levados à busca coletiva de alternativas. É um espaço de comunicação que tem por inspiração matricial teórica os temas geradores de Paulo Freire. Utilizando a técnica de brainstorming (tempestade cerebral), cria uma relação dialógica entre professores e alunos, propiciando ao professor uma oportunidade de mapear e sondar os conhecimentos prévios dos alunos sobre o tema a ser estudado, apontando para o grau de intensidade ou profundidade com o qual as informações novas devem ser veiculadas. Uma representação do tema em segunda linguagem (foto, gravura, música, texto, desenho, reportagem, gráfico, sempre acompanhados da fonte e nome do autor) favorece o diálogo e confere significado à aprendizagem. Também permite verificar que as representações que os alunos têm sobre a realidade diferem quanto ao conteúdo, natureza, escolaridade anterior e estágios de desenvolvimento. Uma ilustração permite certa convergência dessas diferenças e reorganiza os elementos necessários para novas aprendizagens.

Explora-se então o campo 3 - Veja Mais!, posicionado no campo superior direito, que visa enriquecer e desequilibrar os alunos, trazendo novos vínculos ao tema apresentado (biografias, fotos, tabelas, índices estatísticos, vídeos, leituras paralelas, curiosidades), em 
uma variedade de enfoques multidisciplinares. Ao confrontar conhecimentos tácitos ou do senso comum com os saberes escolares, introduz o conflito, conferindo diferentes graus de significado e provocando novos desequilíbrios ao conhecimento já adquirido. A apresentação de situações de diferentes complexidades requer o manejo de amplos conjuntos de informações (explicações históricas, geográficas, específicas de conceitos e princípios de determinadas áreas de conhecimento etc.). Nesse sentido, o professor exerce o papel de provocador cognitivo, propiciando condições para que a sala de aula se transforme em uma oficina ou ateliê de aprendizagem.

O campo 4 - Faça Você Mesmo! é dedicado aos conteúdos procedimentais e incorpora as propostas cognitivas de diversos autores (Piaget, Bruner, Ausubel e Vygotsky). Propõe que os alunos desenvolvam habilidades cognitivas e metacognitivas, através da formulação de hipóteses, estimativas, anotações, esquemas, croquis, organogramas e esquemas de suas ações, planos e generalizações. Objetiva estabelecer semelhanças com experiências e procedimentos anteriores, analogias e relações com aprendizagens anteriores. Aqui se encaixam atividades de aprendizagem tais como seguir instruções para a solução de problemas, estabelecer semelhanças com experiências de procedimentos anteriores, criar analogias, situar a aprendizagem em relação a outras já realizadas. Pela metacognição, os alunos podem antecipar e identificar erros, verbalizar as situações e atividades planejadas, compartilhar com os colegas do grupo a resolução de problemas, negociando e confrontando idéias.

Nossa Língua! (campo 5) torna a Língua Portuguesa transversalmente presente em todos os momentos de aprendizagem, valorizando a leitura, a produção escrita, a análise e a reflexão em situações reais de uso, e não como conteúdos estanques de uma disciplina independente. A Língua Portuguesa é tratada não como disciplina estanque, mas como instrumento de estudo dos próprios textos e atividades do episódio-aula. Assim, a expressão oral, a leitura, o entendimento e o registro escrito da palavra se manifestam em habilidades do aluno de recordar e evocar o que está em sua memória, empregar vocabulário adequado, definir, exemplificar, caracterizar, estabelecer relações, apontar diferenças conceituais, empregar suas próprias palavras para definir conceitos e princípios científicos e buscar formas de expressão alternativas.

O campo 6, no campo superior esquerdo do verso da ficha, é dedicado à inserção de textos informativos clássicos, extraídos de manuais didáticos, enciclopédias, dicionários, 
fontes originais ou artigos de periódicos e faz referências conteúdos curriculares científicos e culturais-sociais considerados relevantes. Esses conhecimentos exprimem por meio de símbolos, signos verbais, numéricos, musicais, plásticos, históricos e científicos o que as gerações mais velhas desejam que seja transmitido às novas gerações. A legitimidade do texto é garantida pela citação de sua fonte e autor.

O campo 7 - Fatos, conceitos e princípios apresentam de forma objetiva os conhecimentos a serem construídos com os alunos. Observa-se que esse campo remete a estratégias de aprendizagem diferenciadas: fatos são aprendidos pela memória; conceitos requerem aprendizagem significativa; princípios (conceitos estruturantes mais gerais) exigem alto nível de abstração (PICONEZ, 2004a, p. 21).

Teckné - Arte e Tecnologia (campo 8) é o espaço interdisciplinar por excelência, para expressar a imaginação e a reflexão do homem em relação à realidade e reconhecer ou compreender a diversidade de concepções estéticas presentes na história da criação humana. No planejamento, os professores buscam a convergência de conhecimentos, ou seja, as interligações possíveis entre manifestações da liberdade humana (pintura, escultura, música, teatro, culinária, artesanato, moda, folclore etc.) e os conteúdos eleitos para aquela unidade temática.

Refletindo (campo 9) é um campo interdisciplinar dedicado aos conteúdos atitudinais e ao tratamento das problemáticas sociais com relevância sócio-cultural e política (discussão de valores básicos para o exercício da cidadania; respeito à diversidade étnicasócio-política-cultural e de todo tema transversal indicado nas respostas curriculares oficiais: orientação sexual, consumo, saúde, meio ambiente, ética e convívio social, pluralidade cultural, direitos e deveres, códigos e leis e outros). Este campo permite verificar como ocorrem as transferências de aprendizagem dos fatos, conceitos, princípios e habilidades dos alunos.

O campo 10 - Planejando Seus Estudos se destina ao planejamento dos recursos que poderão ser utilizados pelos alunos virtual e/ou presencialmente, funcionando também como notificação ao professor e à equipe pedagógica a respeito dos materiais que devem ficar disponíveis aos alunos para suporte a determinada unidade temática. 
O campo 11 - Avaliando competências básicas registra o paradigma de avaliação, com as competências básicas e as habilidades que cada tema tratado pode desenvolver.

As Fichas Temáticas são complementadas por Folhas-Anexas, que incluem textos, letras de música, poesias, quadros, notícias, fotos, tabelas, gráficos, recortes etc., e FolhasTarefa, destinadas à realização de atividades pelos alunos.

Para desenvolver um sistema de apoio ao aprendizado do público adulto atendido pelo NEA, o Departamento de Recursos Humanos da Reitoria da USP disponibilizou uma equipe de programadores que receberam a assessoria dos pesquisadores do Laboratório de Informática da FEUSP. Inicialmente destinado às demandas do Curso de Ensino Médio a Distância, o ambiente pouco a pouco foi incorporando várias das funcionalidades existentes em outros sistemas.

Durante essa evolução tecnológica, o ambiente tornou-se mais robusto e voltado para o planejamento de ações de aprendizagem tanto pelos alunos como para os professores. Espelhando o projeto político pedagógico do NEA, o ambiente também procurou subverter a lógica conteudista, baseada na mera entrega de informações, considerando para isso a disponibilização de unidades e módulos de estudo, bem como a realização de projetos com apoio das tecnologias.

Reconhecendo os avanços recentes da tecnologia, em especial da tecnologia em rede, o Portal também se revelou como possibilidade de compartilhar os fundamentos teóricos e as aplicações práticas, disponibilizando-se material de apoio pedagógico a alunos e professores. O Portal possibilita a geração de pesquisa colaborativa através do intercâmbio e interação com diferentes áreas de conhecimento, instituições e pessoas, bem como a produção de mecanismos de acompanhamento e avaliação sistemática das alternativas e possibilidades de formação à distância, nos níveis médio e fundamental, educação continuada e formação para a cidadania.

O SIGEPE - Sistema de Gerenciamento de Informações Pedagógicas é a ferramenta que sistematiza e automatiza o processo de criação e atualização de informações no Portal NEA (RODRIGUES et al., 2006). Tem por objetivo a criação, a edição e o gerenciamento das informações publicadas no via Web. As páginas são geradas 
dinamicamente a partir de um banco de dados, e o SIGEPE pode ser operado através de qualquer browser Web.

A interface é independente da plataforma ou sistema operacional, possibilitando a execução de diferentes tarefas a partir do mesmo, tornando desnecessária a instalação de software adicional. Isso permite que todo o conteúdo do ambiente esteja disponível em qualquer lugar desde que esteja conectado à Internet.

\section{ANÁLISE MULTIDIMENSIONAL DO STEA}

A partir daqui, analisamos o STEA - o Sistema Transversal de EnsinoAprendizagem em suas múltiplas dimensões - pedagógica, semântica, tecnológica, do aluno e organizacional.

\section{Dimensão pedagógica}

Sistemas para aprendizado eletrônico

Em termos de práticas pedagógicas apoiadas por tecnologias, o STEA acompanhou as gerações da educação a distância, principalmente em termos de mídias utilizadas (material impresso, vídeo, Internet); no que diz respeito aos sistemas de aprendizado eletrônico, contudo, algumas particularidades devem ser destacadas. Ao longo de seu desenvolvimento e utilização, o STEA prescindiu de sistemas de gerenciamento da aprendizagem (LMSs) para a execução de funções administrativas tais como matrícula e monitoramento dos alunos, sendo estas funções realizadas por meio de softwares comerciais não integrados.

Assim, a não adoção de um LMS para o Curso de Ensino Médio não se explica pela inexistência de infra-estrutura ou competência técnica, pedagógica e gerencial. Pode explicar-se pelo fato de os LMSs estudados pelos professores e coordenação científica (WebCT (2001), VirtusClass (2002), Wiki (2003), COL (2004) e Moodle (2005 em diante) não proporcionarem o ambiente virtual de aprendizagem adequado ao STEA - seja por não possibilitarem a realização de atividades de design, execução e acompanhamento das Fichas Temáticas de Apoio Pedagógico, centrais à metodologia, seja devido ao nível de fluência digital exigido de professores e principalmente alunos. Além disso, em termos de priorização de uso de recursos, a necessidade de desenvolver um portal para armazenar e disponibilizar 
informação dinâmica referente às ações do Curso de Ensino Médio precedeu a exigência de adotar um LMS.

O STEA avançou assim direto para a segunda e a terceira ondas de sistemas de aprendizado eletrônico. O SIGEPE (Sistema de Gerenciamento Transversal de Conteúdos) tornou-se uma alternativa para as limitações dos LMSs e LCMSs disponíveis, porém sem a preocupação de aderir a padrões de metadados que caracterizam os gerenciadores de conteúdos, ou a padrões de interoperabilidade educacional representados pelo IMS Learning Design.

Não podemos categorizar o SIGEPE como uma sistemática “inspirada” no Learning Design, visto que sua estruturação se deu paralelamente às discussões internacionais sobre a EML e o IMS LD. Podemos, contudo, identificar no STEA elementos do LD, o que nos permite inferir, por um lado, que a evolução natural do STEA caminha em direção à abordagem de Learning Design mais ampla, e, por outro, que as discussões internacionais sobre LD ecoam em certa medida a prática pedagógica nacional.

Metamodelo pedagógico

Um modelo pedagógico é definido como um conjunto de regras e condições que, inspirados por teorias de aprendizagem e instrução, prescrevem de que forma os alunos podem atingir determinados objetivos de aprendizagem, em determinados contextos e domínios de conhecimento, da maneira mais efetiva.

Essa compreensão dos fenômenos educacionais, registrada no Projeto Pedagógico (nível macro) se traduz em um (micro) design instrucional flexível, baseado em episódiosaula que permitem a convergência de estratégias pedagógicas variadas.

No que tange à adesão a um metamodelo pedagógico formal como a EML ou a abordagem de Learning Design, o STEA também trabalha sobre um modelo conceitual de atividades dispostas em unidades de aprendizagem elementares (Fichas Temáticas), que funcionam em um cenário de aprendizagem, uma espécie de "história” estruturada (os episódios-aula). 
Dessa forma, a máxima de Hummell et al. (2004), segundo a qual:

\begin{abstract}
as pessoas agem em diferentes papéis no processo de ensino-aprendizagem, buscando certos resultados pela realização de atividades de aprendizagem e/ou suporte, dentro de um ambiente constituído em objetos e serviços de aprendizagem a serem usados durante o desempenho dessas atividades . E pode ser aplicada ao STEA nos seguintes termos: "as pessoas envolvidas no Curso de Ensino Médio agem em diferentes papéis (como alunos autônomos ou membros de uma comunidade de aprendizagem, como professores em formação, como equipe pedagógica, administrativa ou tecnológica) no processo de ensino-aprendizagem, buscando o atendimento da escolaridade em nível de ensino médio, bem como a formação de professores-estagiários em serviço, dentro de um ambiente presencial e/ou virtual constituído de Fichas Temáticas de Apoio Pedagógico, Portal NEA e SIGEPE a serem usados durante o desempenho dessas atividades.
\end{abstract}

Devemos destacar que no STEA as conexões entre as unidades de aprendizagem não se dão em termos de pré-requisitos, mas de hiperlinks que estabelecem relações entre as unidades temáticas de uma mesma disciplina e entre eixos curriculares distintos. Ou seja, mesmo que as unidades temáticas que compõem o Curso de Ensino Médio sejam identificadas por uma ordem numérica, o aluno pode explorá-las livremente, visto que estão todas disponíveis para acesso no Portal NEA.

Quanto à estrutura interna das atividades de aprendizagem, representadas pelos diferentes campos das Fichas Temáticas, o STEA recomenda uma exploração seqüencial (PICONEZ, 2004a, p. 18-24), a despeito da sua construção e disposição visual hipertextual: “Inicia-se o episódio-aula... com uma pergunta desafiadora ou problematizadora” (p. 18); “ $\mathrm{Na}$ seqüência, a utilização de uma segunda linguagem... (p. 18) “; “... na seqüencia do trabalho do professor, o campo intitulado Veja Mais!...” (p. 18); “Na seqüência, no campo Faça Você Mesmo!” (p. 19), “Até este momento, estes campos caracterizam...” (p. 20) (grifos nossos).

O pré-seqüenciamento das atividades de ensino-aprendizagem também se traduz na distribuição dos campos na frente e no verso das Fichas Temáticas. Se na parte frontal, o foco é na coleta de dados (em linguagem de projetos, problematização do tema, levantamento dos conceitos tácitos dos alunos), o verso é dedicado à sistematização da aprendizagem, enquanto as Folhas-Tarefa funcionam como suporte para registro das atividades dos alunos.

\title{
Learning Design e design instructional
}

Conquanto no âmbito do STEA não exista a figura do designer instrucional clássico, é inquestionável a existência de uma inteligência de design instrucional no sistema. Seja porque qualquer prática de aprendizagem possui um design de aprendizagem subjacente 
(KOPER; TATTERSALL, 2005, p. 4), seja porque as concepções pedagógicas assumidas são traduzidas em produtos visíveis - originalmente as Fichas Temáticas e em uma etapa posterior os recursos tecnológicos incorporados ao sistema -, o STEA comporta processos e decisões de design instrucional.

Em nível macro, há que se considerar o trabalho de design instrucional consolidado pela coordenação científica nas Fichas Temáticas de Apoio Pedagógico, que funcionam como gabaritos (templates) para planejamento e design, sendo utilizadas também nas fases de execução dos episódios-aula - uma solução formatada com base no contexto específico de pesquisa e prática da educação a distância do NEA.

A estrutura de campos predefinidos segundo a abordagem freireana serve como ponto de partida para o planejamento dos professores e para o microdesign dos materiais didáticos, reorganizados bienalmente a cada novo grupo de professores-estagiários que se vincula ao Programa de EJA.

Em nível micro, uma equipe multidisciplinar realiza os processos clássicos de design instrucional para cada Ficha Temática. A análise, design, desenvolvimento, implementação e avaliação de soluções estão explicitados na preocupação com a linguagem usada, na organização da informação interna a cada unidade temática e entre disciplinas, na definição de objetivos de aprendizagem e competências a serem desenvolvidas a cada unidade, na preparação de espaços para a construção de significados pelos alunos.

A capacitação e o planejamento e design estão diretamente voltadas à formação de professores, enquanto a execução de episódios-aula e a avaliação concentram as ações de educação de jovens e adultos para o Ensino Médio. Todavia, compõem um todo integrado, uma vez que os professores-estagiários são capacitados a planejar, executar e avaliar continuamente suas ações.

Na fase de execução dos episódios-aula, a distinção entre os papéis “Grupo de alunos" (o conjunto total de alunos que freqüenta plantões presenciais públicos) e "Aluno" (aquele estuda de forma independente e totalmente a distância) se dá no nível das ferramentas. Ou seja, alunos reunidos em grupo nos plantões presenciais manipulam material didático impresso e comunicam-se com o professor e os colegas de estudo presencialmente, enquanto alunos independentes acessam material didático digital (em formato portável), com 
possibilidade de realizar as atividades em uma Folha-Tarefa também digital (em formado de documento), e comunicam-se com o professor via fórum. Vale lembrar que a estrutura geral desta fase se repete para cada um dos episódios-aula. Ainda na fase de execução, podemos notar que ferramentas de professor-estagiário e grupo de alunos são as mesmas, o que é resultado do design original do STEA, que reúne em um único artefato (impresso) o plano orientador do episódio-aula que orienta o professor e o material didático a ser manipulado pelo aluno.

Destrinchar a narrativa do Curso de Ensino Médio a Distância, em "atividades de aprendizagem” e “de suporte” para os diferentes papéis que compõem o cenário de aprendizagem, com seus respectivos conteúdos, ferramentas e outros elementos que se queira adicionar, requer um nível de detalhamento incomum mesmo em sistemas pedagógicos estruturados como o STEA.

Tal pormenorização é um exercício de objetivação da prática educacional que visa, em primeira instância, identificar os elementos a serem informados ao sistema na fase de autoria do learning design, e ao mesmo tempo se constituir em uma estratégia de explicitação do método de ensino-aprendizagem. Ao arrolar e vincular papéis, atividades, conteúdos, ferramentas, produção dos atores, práticas de avaliação, entre outros, o que se faz é traduzir a filosofia pedagógica que inspira o macrodesign instrucional em micro-estratégias que tornarão concreto o processo de ensino-aprendizagem.

\section{Dimensão semântica}

Como dissemos anteriormente, o STEA construiu um modelo próprio para atender às necessidades específicas de seu contexto de aprendizagem (formação de professores em serviço e educação de jovens e adultos para o ensino médio).

Podemos afirmar que o STEA é um sistema notacional, já que se utiliza de um conjunto de signos e ícones para representar um problema e assegura a duplicação, execução e comunicação de uma solução.

No quesito intuitividade, o STEA parece bem mais próximo às imagens mentais dos usuários (principalmente professores-estagiários) do que o LD, em especial porque reflete certa concretude em relação ao uso de tecnologias para apoio a atividades presenciais. 
Os papéis, por exemplo, estão mais vinculados ao status administrativo dos participantes ou aos privilégios dos usuários no SIGEPE, embora os professores-estagiários, por exemplo, tenham atribuições distintas nos vários atos (fases) do programa (alunos na capacitação, designers instrucionais no planejamento, professores nos plantões presenciais, moderadores nos fóruns virtuais).

A tecnologia é considerada mais um conjunto de recursos complementares (conteúdos digitais, serviços de comunicação) do que um ambiente no qual ocorrem todas as relações de aprendizagem e ensino (suporte). Assim, no continuum de uso de tecnologias para o aprendizado eletrônico, o STEA se localizaria atualmente no padrão suplementar.

Nesse cenário de uso (Fichas Temáticas digitalizadas + ambiente de interação virtual), as propriedades e condições não são explicitadas, pois não é preciso informar ao sistema, variáveis que facilitariam o rastreamento e a análise processual da aprendizagem.

A adesão à abordagem genérica de Learning Design parece simples do ponto de vista do STEA, uma vez que seria necessário apenas aproximar vocabulários e relações das duas ontologias. Aderir à especificação IMS LD, contudo, implicaria caminhar para usos essenciais e colaborativos da tecnologia e para o processamento automático do design instrucional projetado.

No estágio atual, o STEA descreve formalmente unidades de aprendizagem e registra explicitamente a estrutura dos componentes instrucionais, permite a reprodutibilidade e a reusabilidade das unidades de aprendizagem descritas, abrangendo o ciclo completo de produção, adaptação armazenamento, distribuição e arquivos das unidades de aprendizagem.

É, de certa forma, neutro em termos de mídias, uma vez que, como dito anteriormente, atravessou as várias gerações de educação a distância, incorporando diferentes mídias para apoio ao aprendizado. Adota uma posição pedagogicamente rica, comportando estratégias de aprendizagem diferenciadas, e está longe de ser pedagogicamente neutro, como se espera de um metamodelo pedagógico. Isto porque o STEA é um subsistema notacional, construído para uma realidade educacional específica, enquanto o LD tenciona ser abrangente o bastante para apoiar variados subsistemas. 
O STEA e suas ferramentas tecnológicas, contudo, não são compatíveis com os padrões ou e especificações de interoperabilidade disponíveis. Nesse sentido, a adesão ao LD poderia aumentar sua capacidade de conversão e resistência a mudanças técnicas.

O STEA oferece suporte e encorajamento à improvisação; o LD, por sua vez, exige antecipação dos processos de ensino e aprendizagem, pressupondo uma curva de aprendizagem mais íngreme para professores desempenhando o papel de designers instrucionais, dado o nível de detalhamento requerido. Por outro lado, se considerado uma ferramenta de pensamento, o LD favorece a explicitação das premissas pedagógicas, por vezes inconscientes, que influenciam a prática.

Ao permitir a representação das atividades de aprendizagem e de suporte, e a sincronização de papéis em atos, o LD torna explícitas as relações entre alunos e equipe, contribuindo para a reflexão na e sobre a ação de design e execução de episódios-aula.

Em termos de interpretabilidade, os campos das Fichas Temáticas do STEA em geral projetam atividades ajustáveis às características do contexto. Comparativamente, embora pareça que o LD impeça interpretações variadas ao exigir uma especificação tão detalhada na fase de autoria, ele potencialmente pode definir as mesmas estratégias de aprendizagem que os campos do STEA definem - espaços de troca, discussão e reflexão, a saber, toda a prática decorrente de uma abordagem pedagógica baseada no (sócio) construtivismo.

Evidencia-se assim que a sensibilidade ao contexto não está no tipo de atividade proposta, mas na coordenação das atividades de aprendizagem e de suporte em um fluxo; em outras palavras, não está, por exemplo, em atividades de discussão, mas no que se faz com os resultados da discussão na estrutura de atividades proposta.

Na educação convencional, a sensibilidade ao contexto se dá na fase de execução, pela atuação do professor, que decide cursos de ação diante das variáveis contextuais que se apresentam. No aprendizado eletrônico, a sensibilidade ao contexto é definida na fase de design.

O ponto crítico está então na capacidade de adaptar a estrutura das atividades com base nas preferências, em conhecimentos prévios, necessidades educacionais e circunstâncias 
situacionais, assim como na possibilidade de atribuir o controle desses aspectos, conforme desejado, aos atores do processo ou ao próprio computador.

Para isso, é preciso analisar mais detalhadamente os recursos tecnológicos do STEA da perspectiva das ferramentas de Learning Design disponíveis.

\section{Dimensão tecnológica}

Embora o STEA tenha sido criado originalmente para o suporte impresso, podemos traçar um paralelo entre a incorporação de tecnologias ao STEA e as diferentes gerações da educação a distância que avançam das tecnologias distributivas e interativas para as tecnologias colaborativas. Isso se verifica pelo emprego de uma variedade de recursos audiovisuais (vídeos, tele-aulas, programas de rádio etc.) e posteriormente da Web (com a rede de hiperlinks complementares apresentados no interior das Fichas Temáticas, os processos de digitalização e entrega de arquivos digitais via Internet para acesso a distância pelos alunos, e os serviços de comunicação eletrônica como fóruns) para apresentação dos conteúdos curriculares e para a interação entre professores e alunos.

Assim, os recursos tecnológicos foram sendo incorporados ao STEA à medida que se fizeram necessários. A primeira ação foi a digitalização das Fichas Temáticas, convertidas em arquivos no formato portável (PDF - Portable Document Format), que podiam ser baixados em qualquer hora ou lugar, reduzindo-se os custos de impressão e facilitando a logística de entrega.

Posteriormente, foi desenvolvido e implementado o fórum de discussão e dúvidas para que os alunos pudessem consultar os professores a distância via comunicação assíncrona. Da perspectiva do planejamento de ensino, criou-se um gerenciador de conteúdos (SIGEPE), para que inicialmente as fichas prontas fossem armazenadas e catalogadas; posteriormente esse gerenciador abarcou o processo completo de elaboração das fichas, disponibilizadas aos alunos pelo Portal NEA. 
Ferramenta de autoria

Hoje, a equipe do NEA utiliza editores de texto e algumas outras ferramentas de autoria de conteúdos para montar as Fichas Temáticas, enquanto um especialista em tecnologia opera o SIGEPE - Sistema de Gerenciamento de Conteúdos Pedagógicos.

Uma ferramenta de autoria, não substituiria as ferramentas atualmente usadas para planejamento e design dos episódios-aula. Suas funções estão restritas ao empacotamento de conteúdos eletrônicos segundo uma estrutura de atividades, à sua descrição em termos de metadados, e logicamente à possibilidade de articular esses conteúdos com papéis e ambientes (o que o diferencia o LD de outras abordagens, como o SCORM).

Igualmente não substituiria o SIGEPE, cujos próximos desenvolvimentos poderiam, caso fosse adotado de fato o padrão de interoperabilidade IMS LD, incluir recursos de edição XML, edição de metadados e integração das ferramentas de fórum e correio eletrônico.

Repositórios

O armazenamento e a reutilização de unidades de aprendizagem fazem parte da prática do STEA desde o seu princípio. Portanto, a idéia de reuso é bastante familiar. Apenas com a digitalização das Fichas Temáticas, porém, é se tornou possível a localização rápida por palavras-chave, mas ainda de maneira simples por meio de mecanismos de busca próprios de programas como o Windows, por exemplo. O SIGEPE caminha no sentido de tornar-se um repositório das Fichas Temáticas e de objetos de informação que podem ser referenciados na sua elaboração. A adesão do STEA à especificação IMS LD e o armazenamento de pacotes LD traria como benefícios a possibilidade de busca indexada. Mesmo levando em consideração as particularidades de cada área de conhecimento, o STEA é abrangente e flexível o suficiente para comportar uma diversidade de estratégias pedagógicas, justamente o que o torna um exemplo de design instrucional contextualizado e um bom candidato para análise do Learning Design.

Desde a sua criação, o STEA já é um template, uma estrutura básica sobre a qual são organizadas e construídas adaptações conforme os contextos de uso. Quer no formato texto, quer no formato digital (processado com editores de texto e convertidos em arquivos 
portáveis), as Fichas Temáticas garantem a aplicação do método como estruturado atualmente. Dessa forma, o planejamento, design e desenvolvimento dos materiais seguiriam os mesmos processos atuais, com um designer da aprendizagem alimentando o editor de atividades com arquivos em formatos .doc. xml, .html e .pdf e gerando pacotes LD para exibição via Player.

No modelo atual de aplicação do STEA, a contextualização do design instrucional expresso nas Fichas Temáticas é assegurada por mecanismos simples de alternância entre freqüentar os plantões presenciais e concluir as unidades de estudos de forma independente, não exigindo explicitação ou cumprimento de condições para sua realização.

As propriedades pessoais que comporiam o dossiê portável entre diferentes unidades de aprendizagem são na realidade arquivadas em prontuários físicos individuais, prática exigida por lei e que tem alcançado êxito no atual estágio de aplicação do STEA. Não obstante, em uma adoção mais intensa do Learning Design para o STEA, podem ser utilizadas propriedades relativas a papéis (locais) para diferenciar atividades ou estruturas de atividades conforme o desempenho dos alunos. Da mesma forma, os recursos de notificação do Nível C dependeriam de informar ao sistema condições relacionadas a essas propriedades, para disparar novos atos, novas partes de papéis, novos recursos ou novas atividades, simulando de certa forma as adaptações hoje realizadas no presencial, que extrapolam um único percurso rígido e linear.

Portal e serviços

O Portal NEA é o ponto de entrada aos conteúdos e serviços do contexto estendido do STEA. Está aberto a qualquer visitante, que pode navegar livremente pelas áreas do Portal. A autenticação de usuários se dá no SIGEPE, como descrito anteriormente, e ferramenta a ferramenta (por exemplo, no fórum).

A adesão à especificação IMS LD pressupõe a integração entre o Player e os serviços de comunicação, de modo que dados do dossiê dos participantes possam ser compartilhados entre os sistemas. 


\section{Dimensão do aluno}

Dada a ausência de ferramentas de autoria e execução “prontos para uso” em idioma nacional, e também pelo foco delimitado desta pesquisa, nossas observações sobre a dimensão do aluno no aprendizado eletrônico segundo a perspectiva do Learning Design se referem às fases de autoria, instanciação e execução com usuários fictícios.

\section{Interface humano-computador}

Desde a criação, o STEA reflete o seu design instrucional subjacente em um design de superfície, a princípio impresso (as Fichas Temáticas de Apoio Pedagógico) e posteriormente convertido para o meio eletrônico e hipertextual (Fichas Temáticas disponibilizadas em formato digital portável e funcionalidades extras acessível no Portal NEA).

O desafio de traduzir para o ambiente virtual o material didático testado e aprovado ao longo de anos de utilização exigiu ajustes operacionais simples tanto quanto possibilitou a concretização de pressuposições teóricas do STEA.

Originalmente, as Fichas Temáticas dos diferentes eixos curriculares eram impressas em texto preto sobre papel colorido, a fim de facilitar a identificação pelos alunos. Com a digitalização e disponibilização virtual das Fichas Temáticas, as cores identificadoras migraram do papel para o plano de fundo dos arquivos de texto, assim como puderam ser conservadas as cores originais das imagens utilizadas como segunda linguagem no Campo 2 Pergunta Problematizador / Tema gerador, ficando à escolha do aluno imprimir em preto-ebranco ou no formato colorido.

Recursos de hiperlinkagem interna (a temas transversais disponíveis no Portal NEA e a Fichas Temáticas relacionadas) e externa (a sites públicos recomendados) também se somaram aos benefícios potencializados pela mídia eletrônica, ampliando as possibilidades de concretizar os princípios da transversalidade na abordagem de temas.

Desde a primeira versão do STEA (modelo impresso), é o aluno quem decide por qual Módulo ou Ficha iniciar os estudos, a partir de um fichário de materiais impressos; com a virtualização das Fichas, os alunos passaram a acessar (e imprimir) os materiais apenas 
quando necessário. Paulatinamente, foram incorporados ao STEA serviços de comunicação a distância (fóruns assíncronos e formulário de correio eletrônico) e mecanismos de busca interna (Google).

Lidar com os novos recursos virtuais disponíveis no Portal NEA exigiu a capacitação de professores e a inclusão no currículo do Curso de Ensino Médio de um módulo de fluência digital para os alunos, realizado no Laboratório de Informática, com a orientação dos professores, assim como a elaboração de um Guia Tutorial de Apoio ao Ensino Médio específico (PICONEZ, 2005a).

A oferta aos alunos do Curso de Ensino Médio de possibilidade de ação (affordances), como acesso on-line a materiais, professores e conjuntos de informações complementares, para livre exploração ou a partir de links nas Fichas Temáticas, independentemente de tempo e local, e em ambiente de aprendizagem seguro como o Portal NEA, por si só representa um avanço na inclusão desses indivíduos no mundo digital.

Da perspectiva do Learning Design, organizar os recursos tecnológicos em ambientes atrelados a atividades de aprendizagem pode, por um lado, reduzir a sobrecarga cognitiva dos alunos, pela delimitação do foco de exploração; por outro, pode aumentar a carga de direcionamento do design instrucional, contrariando o pressuposto do autodirecionamento na aprendizagem de adultos.

\section{A Geração Net e a Educação de Jovens e Adultos}

De certo, o aprendizado eletrônico tem significados e implicações diferentes para a geração Net e adultos em processo de escolarização tardia. Em linhas gerais, identificamos certa semelhança no que diz respeito à exploração transversal e não-estruturada da realidade, e certa distinção quanto à capacidade de influenciar essa realidade, produzindo e publicando seus próprios registros.

No caso específico dos alunos do Curso de Ensino Médio a Distância - contexto ampliado do STEA, nosso objeto de pesquisa -, apenas o fato de pertencerem a gerações mais velhas, de atuarem profissionalmente em funções menos vinculadas a experiências digitais, e de possuírem uma carga de pressuposições e conhecimentos prévios heterogêneos, 
relacionados à vivência, à vida profissional, à família, à expectativa de vida, implica uma ação pedagógica diferenciada daquela praticada com alunos do ensino médio regular.

Ao longo dos vários anos de existência do Programa de EJA - Educação de Jovens e Adultos, PICONEZ (2003b) mapeou características presentes no grupo de alunos adultos, funcionários da USP:

- Os adultos só aprendem se quiserem: Os adultos são práticos, desejam saber em que o ensino o auxiliará de imediato. Não se interessam por algo que poderá servir-lhes dentro de dez anos, daí a dificuldade de motivação para estágios longos. Isso significa que os adultos desejam aprender alguma coisa no decorrer de cada encontro. É importante que uma situação de ensino-aprendizagem lhes comunique a sensação de que tiraram dali algum resultado útil. Eles se impacientam facilmente diante de muita teoria ou preâmbulos: reagem melhor se lhes ensinarem, simples e diretamente, o que querem aprender.

- Os adultos aprendem pela prática: A experiência tem demonstrado que colocar em prática de forma imediata e contínua os conteúdos estudados colabora para consolidar a sua aquisição. Se os adultos não têm a possibilidade de envolver-se ativamente no ensino, esquecem rapidamente o que aprenderam. Por essa razão, é preciso encorajálos a discutir um problema, a elaborar uma solução, a praticar uma maneira de fazer. Os adultos aprendem resolvendo problemas ligados à realidade - Se os problemas não tiverem relação com a realidade, se não forem vivenciados, não se interessarão por eles. É preciso, pois, apresentar-lhes problemas práticos, próximos de sua realidade.

- A experiência afeta a maneira de aprender dos adultos: Eles estabelecem uma ligação entre o que estão aprendendo e o que já sabem. Se os conhecimentos não se enquadram com os que já têm, serão rejeitados. Os adultos têm mais experiência do que as crianças, o que pode ser uma vantagem ou uma desvantagem: uma vantagem, quando tiverem mais possibilidades de unir aquilo que aprenderam àquilo que já sabem; uma desvantagem, quando esta correlação não for mais possível.

- Os adultos aprendem melhor num ambiente descontraído: O meio ambiente não deve lembrar muito uma sala de aula. Muitos adultos guardam uma lembrança humilhante da escola e não desejam que se lhes recorde essa época. Além disso, um ambiente demasiado "escolar" corre o risco de lhes parecer infantil. 
- Os adultos apreciam métodos complementares: Como as crianças, eles compreenderão melhor se lhes apresentar uma mesma idéia de várias maneiras; em outras palavras, quando a informação os atingir pelo canal de mais de um sentido. Bem entendido, o método utilizado dependerá daquilo que lhes é ensinado e dos objetivos visados.

- Os adultos querem ser orientados e não avaliados: É verdade que eles desejam saber como estão trabalhando. Conhecer seu progresso é importante para eles, mas testes ou notas poderão atemorizá-los. Eles tendem a recusar controles, pois receiam não se sair suficientemente bem e ser humilhados.

À primeira vista, é fácil perceber nesse mapeamento uma aproximação com a postura de aprendizagem da geração Net, se abstraída a questão da mediação tecnológica. ${ }^{1}$ Outro estudo de PICONEZ (2003a), porém, indica uma tendência de que alunos adultos com dificuldades para aprender carregam a concepção de aprendizagem como sinônimo de repetição ou memorização, ranço da escolaridade tradicional pelo qual eles próprios passaram ou acompanharam no caso dos filhos.

No entanto, embora os alunos adultos não detenham os códigos formais, nem operem de acordo com esses critérios, eles possuem as estruturas necessárias para compreendê-los. Dados obtidos por entrevistas, fichas informativas e filmagens sobre o cotidiano dos alunos, dentro e fora a escola, com vistas a uma maior compreensão das relações com suas habilidades cognitivas, permitiram identificar alguns dos conhecimentos construídos por eles. Também as estruturas operatórias mais amplas que fomentam suas ações, estruturas estas formadas na vida social, cultural e de trabalho, em suas articulações com a aprendizagem escolar (PICONEZ, 2002, p. 74).

O aprendizado eletrônico pode colaborar para uma mudança de paradigma sobre o que significa aprender e sobre o valor dos conhecimentos construídos fora escola, pela compreensão da escola não como lócus, mas como conceito, e também pelo desenvolvimento e prática de habilidades metacognitivas.

\footnotetext{
${ }^{1}$ Pesquisas realizadas no âmbito do NEA identificaram reduzida porcentagem (em torno de 20\%) no uso de terminais e computadores pessoais e na capacidade de aplicar tecnologia de informações (PICONEZ, 2002, p. 21). Em estudo sobre o significado da informática para jovens e adultos trabalhadores na relação professor-aluno, AGUIAR (2004) observa que os significados atribuídos à informática são construídos em processos socialmente estabelecidos de interação entre sujeitos e em práticas culturais diversas. Enquanto alunos do ensino fundamental atribuem ao computador o significado de ferramenta de trabalho (exposição aos usos vivenciados em situações de trabalho), os alunos do ensino médio atribuem ao computador o significado de propiciar novas formas de aprender (exposição à cultura escolar que incentiva o acesso e a pesquisa de temas escolares).
} 
Cedo ou tarde todo o espectro que compõe a Web 2.0 viabilizará acesso também para alunos adultos a ambientes de aprendizagem pessoais (como blogs, web portfolios) e sociais (como wikis e redes de relacionamento).

Em um cenário ideal, com ferramentas de autoria e exibição de pacotes de LD centradas no usuário, e acoplamento a outras ferramentas via Web services e especificações compatíveis, o modelo atual de uso de tecnologias no STEA poderia ser estendido para proporcionar aos alunos o desenvolvimento e prática de habilidades de comunicação de mão dupla. Eles acessassem o que é produzido e validado por outros, mas também pudessem efetivamente contribuir com idéias, produções e registros em uma rede de aprendizagem significativa.

Modelo de adaptação para o aprendizado eletrônico

Como declara PICONEZ (2003a), quando adultos retornam à escola depois de certa idade, o conhecimento existente não é nada depreciável. Ligado às experiências de vida do adulto, foi construído ao longo de suas interações familiares e nas suas relações de trabalho. A construção do conhecimento escolar exige um processo de negociação entre a definição que o aluno carrega e aquela que o professor ou os materiais didáticos apresentam, para que se chegue a um conhecimento compartilhado. Assim, à medida que os alunos adultos interagem com professores, colegas e conteúdos escolares, podem desenvolver habilidades cada vez mais complexas.

A proposta de design instrucional deve levar em consideração que cada aluno adulto pode partir de diferentes "nós conceituais" para chegar a um novo conceito. Isso equivale a dizer que existem diferentes vias de acesso para chegar ao conceito desejado, porém cada aluno poderá fazê-lo de maneira diferente, utilizando a via que para ele estiver mais desobstruída, ou que para ele faça mais sentido.

Adicionalmente, deve propor problemas a partir dos quais os alunos possam reelaborar conteúdos escolares e promover discussão para que eles considerem a própria opinião e a de seus pares, oferecendo a oportunidade de os alunos coordenarem diferentes pontos de vista e solucionarem cooperativamente situações problemáticas, incentivar a formulação de conceituações necessárias para o avanço no domínio do objeto de conhecimento. 
Esse design instrucional contextualizado é adotado no modelo atual do STEA pela oferta de variadas opções de estudo para o aluno adulto: método individualizado e/ou socializado, modalidade presencial e/ou a distância, plantão de professores síncrono (presencial) ou assíncrono (virtual), mídia impressa e/ou virtual - decisões que podem ser tomadas no nível de eixos curriculares, disciplinas ou unidades temáticas. Isso sem contar os ajustes realizados pelos próprios professores ao atender a necessidades que emergem da interação em “tempo real” (presencial).

Em um sentido, a abordagem de Learning Design pode estender as potencialidades do aprendizado eletrônico para a educação de jovens e adultos, ao oferecer possibilidades de adaptação de atividades, estrutura de atividades ou unidades de estudo a perfis individuais, mantendo ao mesmo tempo a possibilidade de se propor, no mesmo programa e para alunos diferentes, atividades coletivas ou em pequenos grupos.

\section{Dimensão organizacional}

Podemos caracterizar o STEA como um sistema, como a própria denominação diz, pois envolve um conjunto de componentes que fazem sentido quando inter-relacionados. Por essa razão, revela-se um rico exemplo de sistema a ser analisado da perspectiva organizacional do Learning Design.

\section{O STEA como sistema}

Obedecendo às diretrizes curriculares nacionais e à legislação pertinente, o STEA vem sendo empregado no Curso de Ensino Médio a Distância do Programa de EJA Educação de Jovens e Adultos para cobrir o rol completo de disciplinas que compõem a educação regular nacional, requerendo dessa maneira a adequação a metodologias de ensinoaprendizagem variadas.

Está submetido ao sistema educacional mais amplo, por meio do Conselho Estadual de Educação do Estado de São Paulo, às diretrizes do Departamento de Recursos Humanos da Reitoria da USP, além de seguir as normativas da Faculdade de Educação da USP, seu lócus de ação. 
O STEA conta também com um programa de formação de professores-estagiários em serviço, devendo prestar aos cursos de graduação em Pedagogia e Licenciatura da FEUSP. Vale lembrar que esses professores realizam vários dos processos essenciais do aprendizado eletrônico como parte de suas atividades de capacitação.

O NEA funciona como o braço administrativo e de relacionamento com os alunos, ao mesmo tempo em que é um espaço para pesquisa dos alunos de pós-graduação da FEUSP e do Grupo Alpha, resultando em publicações que alimentam o próprio STEA.

O NEA e a Secretaria do Curso de Ensino Médio, vinculada ao Departamento de Reitoria da USP atuam como subsistema de manutenção responsável, incluindo-se aí as ações de capacitação e remuneração dos professores-estagiários, e toda a parte administrativa da vida acadêmica dos alunos.

O Grupo Alpha e os alunos do programa de pós-graduação da FEUSP, juntamente com os próprios professores em formação contínua, entram como parte do subsistema de adaptação, impulsionando inovações e mudanças no sistema de produção, as quais são implementadas para benefício dos alunos do Curso de Ensino Médio e são publicadas nos Cadernos Reflexões Pedagógicas.

Subsistema de produção e modelo de design instrucional

No STEA, equipes de trabalho multidisciplinar supervisionadas pela coordenação científica e pedagógica criam as unidades de aprendizagem (episódios-aula) considerando a organização modular em eixos de conhecimento, o template do STEA e as Fichas Temáticas em outras edições do curso.

O STEA é um bom exemplo de design instrucional contextualizado também pelo histórico de mídias utilizadas. Quando os processos de produção de Fichas Temáticas estavam exclusivamente voltados à mídia impressa, era necessário trabalhar com um design instrucional fixo, uma vez que o conjunto completo de Fichas Temáticas precisava estar pronto em determinado momento para ser encaminhado à reprodução gráfica e à distribuição aos alunos. 
Essas restrições de custos e prazos de produção criaram uma cultura de planejamento, design e revisões anteriores à execução dos episódios-aula que se preservou após a incorporação de tecnologias digitais.

Ao mesmo tempo, como o STEA é um template aberto para planejamento e design, o uso de tecnologias digitais para produção dos materiais abriu a possibilidade de estender o conceito original, que é baseado em design instrucional aberto. Isso significa que o STEA exemplifica o modelo de design instrucional contextualizado não porque combina partes abertas e partes fechadas (o que corresponderia a um modelo de design instrucional aberto), mas porque fixou o design instrucional no nível do template. Objetiva conservar a abordagem pedagógica definida em um nível macro, de programa, e manteve aberto o design das unidades e atividades de aprendizagem (unidades temáticas e campos das Fichas Temáticas), conforme cada novo contexto de utilização.

Essa característica torna o STEA facilmente migrável para o Learning Design, feitos os ajustes conceituais necessários à programação nas ferramentas de autoria, publicação e execução.

O que falta à abordagem de Learning Design é incorporar a possibilidade de adaptações on-the-fly (durante a execução) pelos participantes do contexto, um diferencial do STEA na educação de jovens e adultos, que não pode ser dispensado à custa dos resultados finais.

Web 2.0 e contextualização do STEA

Conforme pesquisa, em termos ideais, a melhor educação on-line é aquela que faz melhor uso das potencialidades da Internet, seguindo a lógica das redes hipertextuais e interativas: livre exploração de recursos, conexão um-a-um, um-a-muitos, muitos-a-muitos, metamorfose dinâmica e descentralização de inteligência e de recursos” (FILATRO, 2004).

O STEA não utiliza a educação $100 \%$ via Web dados os contextos individual, imediato e organizacional do Curso de Ensino Médio, como caracterizamos anteriormente, e também porque os sistemas de aprendizado eletrônico disponíveis (de primeira a terceira onda) não se ajustam, pelo menos até este momento, ao sistema pedagógico-semânticotecnológico-adaptativo-organizacional em vigência. 
Algumas características da Web 2.0, além de desejáveis, podem facilitar muito o trabalho dos professores e alunos do STEA. No entanto, essas mesmas características podem tornar-se um complicador quando disponibilizadas sem um tratamento pedagógico adequado.

Acessar conteúdos e ferramentas diretamente na Web (uma plataforma de acesso), em vez de programas que necessitam de processos de instalação diferenciados e carregam uma lógica de programação própria, pode representar um passo importante para que os participantes do STEA acessem, produzam, editem e publiquem informações digitais, assim como utilizem mais recursos de comunicação eletrônica. A interface e lógica de navegação tendem a ser mais simples devido a adesão a protocolos e padrões, e ao acoplamento de ferramentas de código aberto que em geral são testadas previamente por muitos usuários.

Se, por outro lado, consideramos que a substituição das agendas de lançamento por aperfeiçoamentos contínuos liberados periodicamente, a oferta de “betas” perpétuos pode redundar em caos cognitivo para os alunos adultos, que precisariam gerenciar modificações do ambiente virtual paralelamente às próprias reestruturações cognitivas. Acreditamos que parte dessas dificuldades pode ser administrada pela liberação personalizada de ferramentas no learning design.

Em termos de aproveitamento da inteligência coletiva, a criação dinâmica de conteúdos via blogs e wikis pode ser um desafio considerável no contexto do STEA, devido às habilidades de expressão escrita e de fluência digital requeridas; por outro lado, pode ser um desmistificador dos processos de publicação escrita e virtual, além de um espaço lúdico (uma espécie “tanque de areia”) para aprendizagem colaborativa.

O STEA pode ser a porta de entrada para a participação de alunos e professores em ações de aprendizagem menos estruturadas: redes de relacionamento social, comunidades voltadas a interesses específicos, tais como esportes, passatempos ou cidades de origem, para prática de habilidades de comunicação escrita e oral, e desenvolvimento de competências intelectuais, sociais e artísticas.

No que diz respeito a ambientes pessoais de aprendizagem, e-portfolios ampliados podem ser uma maneira diferenciada de organizar a aprendizagem do aluno adulto e integrá-la à sua história de vida e à sua atuação familiar, social e profissional. Ambientes pessoais também podem espelhar resultados de aprendizagem que extrapolam os conceitos ou notas 
finais das avaliações somativas, funcionando ainda como repositórios dos avanços, descobertas e registros do aluno em seu processo de inclusão escolar, digital e social. Poderiam funcionar ainda como uma preparação para a aprendizagem continuada (lifelong learning).

Em se tratando da filosofia de "conteúdo aberto", embora a maior parte das iniciativas de disponibilização gratuita de conteúdos trabalhe com idiomas estrangeiros, repositórios brasileiros podem complementar a rede de referências já disponíveis no Portal NEA.

Aderindo a padrões internacionais de interoperabilidade, o STEA pode fazer também o caminho inverso, disponibilizando suas experiências, práticas adequadas e expertise acumulada para reutilização em outros contextos de educação de jovens e adultos, uma modalidade de ensino com grandes carências em território nacional e em outros países falantes da língua portuguesa.

A representação inicial do STEA no LD nos permitiu vislumbrar atalhos para uma adoção mais intensa das tecnologias na progressiva virtualização dos processos de planejamento e design instrucional.

O trabalho formador do NEA e as experiências práticas de ensino representam uma ocasião privilegiada para investigar o processo de aprender e ensinar. Os futuros professores reconhecem que as práticas de ensino foram os componentes mais importantes de suas formações além de do que constituem um dos componentes mais destacados da formação inicial dos docentes, pois permitem estabelecer relações entre a formação pedagógica e os institutos de origem. Os estagiários consideram que a formação universitária em educação é sólida na parte teórica, mas carece da dimensão prática. Quando têm oportunidade do exercício da docência saem ganhando na interação dinâmica de sua relação. São reconhecidas como relevantes na tarefa de formação dos professores a existência de um projeto coletivo e proposta pedagógica de educação escolar, a formação de comunidades de aprendizagem, a atitude investigativa como eixo formador consistente e a possibilidade de análise permanente da própria prática pedagógica. 


\section{REFERÊNCIAS}

AGUIAR, T. B. O significado da informática por jovens e adultos trabalhadores na relação professor-aluno. Cadernos Pedagógicos Reflexões / Núcleo de Estudos de Jovens e Adultos e Formação Permanente de Professores (Ensino Presencial e Educação a Distância), São Paulo, v.1, n. 6, p. 95-99, 2004.

BEETHAM, H. Review: developing e-learning models for the JISC Practitioner Communities - version 2.1. 2004. Disponível em:

http://www.jisc.ac.uk/uploaded_documents/Review\%20models.doc

Acesso em: 16 jul.2006.

.Three theoretical approaches to learning, teaching and assessment. Unfold

Communities of Practice, Braga, Jun. 2005. Disponível em: http://www.unfoldproject.net/project/events/cops/portugal/papers/beetham_three_approaches.pdf. Acesso em: 15 mar.2006.

FILATRO, A. Design instrucional contextualizado. São Paulo, SP: SENAC, 2004.

Design instrucional na prática. São Paulo, SP: Prentice/Hall, 2008.

. Learning design como fundamentação teórico-prática para o design instrucional contextualizado. 2008. Tese (Doutorado em Educação) - Faculdade de Educação, Universidade de São Paulo, São Paulo, 2008.

HUMMEL, H.; MANDERVELD, J.; TATTERSALL, C.; KOPER, R. Educational modeling language and learning design: new opportunities for instructional reusability and personalised learning. International Journal of Learning Technology, v.1, n.1, 2004.

KOPER, R. From change to renewal: educational technology foundations of electronic environments. Open University of the Netherlands. 2000. Disponível em http://dspace.learningnetworks.org/ retrieve/37/koper-inaugural-address-eng.pdf. Acessado em: 25/07/2005.

.; TATTERSALL C. (Ed.). Learning design: a handbook on modelling and delivering networked education and training. Berlim: Springer-Verlag, 2005.

PICONEZ, S. C. B. A atualidade da proposta educativa de Paulo Freire. Cadernos Pedagógicos de Reflexões/ Núcleo de Estudos de Jovens e Adultos e Formação Permanente de Professores (Ensino Presencial e Educação a Distância), São Paulo, v. 1, n. 1, p. 9-15, $2004 b$.

. Aprendizagem cooperativa apoiada por recursos da Internet como estratégia de educação permanente e qualificação interdisciplinar. Cadernos Pedagógicos Reflexões / Núcleo de Estudos de Jovens e Adultos e Formação Permanente de Professores (Ensino Presencial e Educação a Distância), v.1, n.6. São Paulo, p. 81-94, 2004c. 
As novas competências para ensinar jovens e adultos e a legislação educacional.

Webteca NEA/FEUSP, s/d. Disponível em: www.nea.fe.usp.br. Acesso em: 18 abr. 2007.

Dificuldades de aprendizagem na educação escolar de jovens e adultos trabalhadores e a abordagem das habilidades metacognitivas. Portal do NEA, 2003a. Disponível em: www.nea.fe.usp.br. Acesso em: 16 abr. 2007.

Dificuldades de aprendizagem na educação escolar de jovens e adultos trabalhadores e a abordagem das habilidades metacognitivas. 2003b. Disponível em: www.nea.fe.usp.br. Acesso em: 18 abr. 2007

. (Org.) Educação básica para jovens e adultos: fundamentos conceituais e referenciais pedagógicos das suas matrizes curriculares para Ensino Médio. Cadernos Pedagógicos Reflexões / Núcleo de Estudos de Jovens e Adultos e Formação Permanente de Professores (Ensino Presencial e Educação a Distância), São Paulo, v.1, n. 3, 2005b.

Educação escolar de jovens e adultos. São Paulo, SP: Papirus, 2002.

Estágios curriculares: matriz epistemológica de integração entre saberes práticos e saberes teóricos na construção do conhecimento didático. Webteca NEA/FEUSP, s/d. Disponível em: www.nea.fe.usp.br. Acesso em: 18 abr. 2007.

. (Org.). Guia tutorial de apoio: ensino médio e portal NEA. Cadernos Pedagógicos Reflexões / Núcleo de Estudos de Jovens e Adultos e Formação Permanente de Professores (Ensino Presencial e Educação a Distância), São Paulo, v.1, n.7, 2005a.

(Org.) Pedagogia de projetos como alternativa geradora de reflexões sobre ensinoaprendizagem na Educação Escolar de Jovens e Adultos. Cadernos Pedagógicos Reflexões / Núcleo de Estudos de Jovens e Adultos e Formação Permanente de Professores (Ensino Presencial e Educação a Distância), São Paulo, v.1, n. 16, 1999.

. Sistema Transversal de Ensino-Aprendizagem: a questão da interdisciplinaridade dos conteúdos curriculares da educação básica. Cadernos Pedagógicos Reflexões / Núcleo de Estudos de Jovens e Adultos e Formação Permanente de Professores (Ensino Presencial e Educação a Distância), São Paulo, v.1, n. 4, p. 9-27, 2004a.

RODRIGUES, A. P. et al. Potencialidades e Desafios das Tecnologias da Informação e Comunicação no Projeto de EJA. In: SIMPÓSIO DE INICIAÇÃO CIENTÍFICA DA UNIVERSIDADE DE SÃO PAULO, São Paulo, 2006. Anais... São Paulo: USP, 2006

ZABALA, A. A prática educativa - como ensinar. Porto Alegre: Artes Médicas, 1998. 
